\title{
Recombinant plant gamma carbonic anhydrase homotrimers bind inorganic carbon
}

\author{
Victoria Martin ${ }^{\mathrm{a}}$, Fernando Villarreal ${ }^{\mathrm{a}}$, Isabelle Miras ${ }^{\mathrm{b}}$, Alda Navaza ${ }^{\mathrm{c}}$, Ahmed Haouz ${ }^{\mathrm{b}}$,

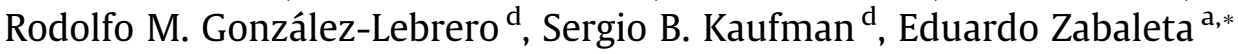 \\ a Instituto de Investigaciones Biológicas (IIB-CONICET-UNMdP), CC 1245, 7600 Mar del Plata, Argentina \\ ${ }^{\mathrm{b}}$ Institut Pasteur, Plate forme 6, URA CNRS 2185, 25, rue du Dr ROUX, Paris 75724, France \\ c ANBioPhi, FRE3207 CNRS-Université Paris6-Université Paris13, 74, rue Marcel Cachin, 93017 Bobigny, France \\ d IQUIFIB-Dpto. Química Biológica, Facultad de Farmacia y Bioquímica, Universidad de Buenos Aires, Buenos Aires, Argentina
}

\section{A R T I C L E I N F O}

\section{Article history:}

Received 29 July 2009

Revised 18 September 2009

Accepted 28 September 2009

Available online 4 October 2009

Edited by Miguel De la Rosa

\section{Keywords:}

Gamma carbonic anhydrase

Carbon dioxide

Carbonate

Mitochondria

Arabidopsis thaliana

\begin{abstract}
A B S T R A C T
Gamma carbonic anhydrases $(\gamma \mathrm{CA})$ are widespread in Prokaryotes. In Eukaryotes, homologous genes were found only in plant genomes. In Arabidopsis and maize, the corresponding gene products are subunits of mitochondrial Complex I.

At present, only $\gamma$ CA homotrimers of Methanosarcina thermophila (CAM) show reversible carbon dioxide $\left(\mathrm{CO}_{2}\right)$ hydration activity. In the present work, it is shown that recombinant plant $\gamma \mathrm{CA} 2$ could form homotrimers and bind $\mathrm{H}^{14} \mathrm{CO}_{3}^{-}$. However, they are unable to catalyse the reversible hydration of $\mathrm{CO}_{2}$.

These results suggest that plant $\gamma$ CAs do not act as carbonic anhydrases but with a related activity possibly contributing to recycle $\mathrm{CO}_{2}$ in the context of photorespiration.

Structured summary:

MINT-7266044: gamma CA2 (uniprotkb:Q9C6B3) and gamma CA2 (uniprotkb:Q9C6B3) physically interact (MI:0914) by dynamic light scattering (MI:0038)

MINT-7266036: gamma CA2 (uniprotkb:Q9C6B3) and gamma CA2 (uniprotkb:Q9C6B3) physically interact (MI:0914) by molecular sieving (MI:0071)
\end{abstract}

๑) 2009 Federation of European Biochemical Societies. Published by Elsevier B.V. All rights reserved.

\section{Introduction}

Plant mitochondrial NADH ubiquinone oxidoreductase (complex I) contains a spherical extra domain in the membrane arm which is specific of eukaryotic photosynthetic organisms [1]. This domain is absent in complex I particles of all other investigated organisms, except for the alga Polytomella, which is closely related to Chlamydomonas. Biochemical data strongly suggest that this extra domain is composed of trimers of gamma carbonic anhydrases $(\gamma \mathrm{CAs})$ facing the mitochondrial matrix. Thus, presence of $\gamma$ CA subunits within complex I correlates with the occurrence of this extra, so-called CA domain.

Carbonic anhydrases (CA-EC 4.2.1.1) are Zn-containing enzymes catalyzing the reversible hydration of carbon dioxide according to the reaction:

$\mathrm{HCO}_{3}^{-}+\mathrm{H}^{+} \rightarrow \mathrm{CO}_{2}+\mathrm{H}_{2} \mathrm{O}$

\footnotetext{
* Corresponding author. Fax: +54 2234753150.

E-mail address: ezabalet@mdp.edu.ar (E. Zabaleta).
}

Currently, five types of CAs ( $\alpha, \beta, \gamma, \delta$ and $\zeta$ ) showing a convergent evolution have been described [2-5]. Gamma type CAs are present in the Bacteria and Archaea domains. In eukaryotes, however, they are found only in photosynthetic organisms [6]. The Arabidopsis $\gamma$ CA protein family is represented by five members. Three of them contain nearly all functionally important amino acids: $\gamma$ CA1 (At1g19580), $\gamma$ CA2 (At1g47260), $\gamma$ CA3 (At5g66510). The two other members are more divergent proteins: $\gamma$ CAL1 (CAL: carbonic-anhydrase-like; At5g63510) and $\gamma$ CAL2 (At3g48680). All five Arabidopsis $\gamma \mathrm{CA} / \gamma \mathrm{CAL}$ subunits were found to be associated with mitochondrial complex I $[7,8]$. All photosynthetic eukaryotes examined so far contain at least one $\gamma$ CA and one $\gamma$ CAL [9]. Structural modelling of these proteins revealed a left-handed- $\beta$-parallel helix ( $\mathrm{L} \beta \mathrm{H})$ conformation [6]. Sequence comparisons showed highest conservation of these proteins to the only biochemical and structurally investigated $\gamma \mathrm{CA}$ (CAM) of Methanosarcina termophila. The functionally important amino acids His 81, His 117, His 122 (zinc coordination), as well as Arg 59, Asp 61, Gln 75, Asp 76 and Asn 202 are conserved between CAM and most of the complex I subunits of plants. Two other functionally important residues (Glu 62 and Glu 84 of CAM) are 
missing, but alternative amino acids which could substitute their roles were suggested [6].

The Arabidopsis $\gamma$ CA2 subunit is exclusively located in the membrane fraction of plant mitochondrial complex I and it is thought to interact with other family members forming trimers. Carbonate treatment of isolated mitochondrial membranes did not allow extraction of the protein, indicating a direct anchoring of $\gamma \mathrm{CA} 2$ within the inner mitochondrial membrane most likely by their C-terminal extensions [7]. Furthermore, protease protection experiments using mitoplasts (mitochondria lacking the outer membrane) suggest that a small part of this protein $(\sim 2 \mathrm{kDa})$ is exposed to the mitochondrial intermembrane space $[7,10]$.

Proteomic and physiological analyses of knock out mutants for each of the CA Arabidopsis genes indicate that only $\gamma C A 2$ appears to be important for complex I assembly since $\gamma \mathrm{ca} 2$ null mutant exhibits only $10 \%$ of normal complex I levels [11]. On the other hand, ectopic over-expression of $\gamma \mathrm{CA} 2$, causes a failure in anther dehiscence and consequently a male sterile phenotype. Impairment of complex I function was detected in these plants [12].

Until present, there is no direct physiological evidence of carbonic anhydrase (CA) activity associated to complex I in plants. Several efforts to determine this activity have been performed using different biochemical fractions, including purified Arabidopsis complex I [11]. Nevertheless, CA activity of this group of plantspecific complex I subunits is strongly supported by computer modelling. As summarized above, most of the residues important for catalysis are conserved between the prototype $\gamma$ CA of Methanosarcina thermophila (CAM) and plant $\gamma$ CAs $[6,10]$. Recently, a related protein from cyanobacteria (Synechocystis CcmM), which is a component of carboxysome (structure involved in $\mathrm{CO}_{2}$ concentration) was shown to bind inorganic carbon. However, carbonate dehydration activity for CcmM has not been detected [13]. CcmM also contains most of the catalytic residues except for Asp 76 and Asn 202 residues (CAM annotation), which are replaced by His and Arg in CcmM, respectively. These residues in CAM are postulated as essential for proton transfer in the $\mathrm{CO}_{2}$ hydration reaction $[4,14]$. Thus, it currently cannot be ruled out that the $\gamma C A$ subunits of complex I do not show CA activity and only bind and perhaps transport $\mathrm{CO}_{2}$ and/or bicarbonate.

In this work, a subunit of complex I, $\gamma$ CA2 was expressed in Escherichia coli in a soluble homotrimeric form, purified to homogeneity and subjected to $\mathrm{H}^{14} \mathrm{CO}_{3}$ binding and $\mathrm{CA}$ activity assays.

\section{Materials and methods}

\subsection{Protein determinations}

Sodium dodecyl sulfate (SDS)-polyacrylamide gel electrophoresis (PAGE) was performed as described previously [15]. In silico analysis of molecular weight and extinction coefficients $(\varepsilon)$ were determined with the Protparam tool (www.expasy.ch/tools/protparam.html). The apparent native molecular mass was monitored by Dynamic light scattering (DLS) using a DynaPro ${ }^{\mathrm{TM}}$ Titan from Wyatt Technology and by using a molecular exchange column (Superose 12/300 GL, GE) equilibrated in buffer A (50 mM NaH $2^{-}$ $\mathrm{PO}_{4}, 150 \mathrm{mM} \mathrm{NaCl}, 1 \mu \mathrm{M} \mathrm{ZnSO}$, pH 7.4) Protein concentration was determined by using the $A_{280}$ with a $\varepsilon: 21555 \mathrm{M}^{-1} \mathrm{~cm}^{-1}$.

\subsection{Bioinformatics}

The mitochondrial signal peptide of $\gamma \mathrm{CA} 2$ was predicted using: MitoProt: mips.helmholtz-muenchen.de/cgi-bin/proj/medgen/ mitofilter, TargetP: www.cbs.dtu.dk/services/TargetP and SignalP: www.cbs.dtu.dk/services/SignalP/. Multiple Sequence Alignment (MSA) was performed with T-coffee: http://tcoffee.vital-it.ch [16].
Sequences used for MSA were 2EG0 (Hypothetical Protein from G. kaustophilus), 1V3W (Ferripyochelin Binding Protein from P. horikoshii), 1XHD (Putative Acetyltransferase from B. cereus), 1QRL (carbonic anhydrase from $M$. thermophila). For secondary structure prediction, Jpred 3 (http://www.compbio.dundee.ac.uk/wwwjpred/) [17] was used.

\subsection{Expression and purification of recombinant $\gamma C A 2$ protein}

RNA from Arabidopsis thaliana was extracted and used for RTPCR with the forward primer: 5'GGGGACAAGTTTGTACAAAAAAGCAGGCTCGGAAAACCTGTATTTTCAGGGCGATAAATCACCATTGGTGGATAAAGATG, and reverse primer: GGGGACCACTTTGTACAAGAAAGCTGGGTTTAATTCTCTGAGGCGTGAATCTGTGC, to generate a recombinant soluble 6XHis-tagged form of $\gamma$ CA2 (aa 50-218). This PCR fragment was cloned using in vitro recombination (GATEWAY, Invitrogen), in the expression plasmid pDEST17. Competent E. coli Rosetta (DE3)pLysS (Novagen) cells were transformed with pDEST17-50-218 (21 kDa). E. coli cells were grown at $30^{\circ} \mathrm{C}$ in LB containing $100 \mu \mathrm{g} / \mathrm{ml}$ of ampicillin and $25 \mu \mathrm{g} / \mathrm{ml}$ of chloramphenicol, and induced at an $\mathrm{A}_{600}$ of $0.6-1$ with $1 \mathrm{mM}$ isopropylthiogalactopyranoside (IPTG). After additional growth for $18 \mathrm{~h}$ at $20^{\circ} \mathrm{C}$, cells were sonicated and resuspended in His binding buffer $\left(20 \mathrm{mM} \mathrm{NaH} \mathrm{PO}_{4}\right.$ y $500 \mathrm{mM} \mathrm{NaCl}, 30 \mathrm{mM}$ Imidazole, $\mathrm{pH}$ 7.4). The soluble protein fraction was collected after centrifugation $\left(10000 \times \mathrm{g}, 30 \mathrm{~min}, 4^{\circ} \mathrm{C}\right)$. Soluble protein extract was applied to His trap HP column (GE Healthcare), then washed with five column volumes with His binding buffer. The His-tagged protein was eluted from the column with elution buffer $(20 \mathrm{mM}$ $\mathrm{NaH}_{2} \mathrm{PO}_{4}, 500 \mathrm{mM} \mathrm{NaCl}, 500 \mathrm{mM}$ Imidazole, $\mathrm{pH}$ 8). The purified recombinant $21 \mathrm{kDa} \gamma \mathrm{CA} 2$ was dialyzed ON against $20 \mathrm{mM} \mathrm{NaH}_{2}$ $\mathrm{PO}_{4}, 100 \mathrm{mM} \mathrm{NaCl}$ and $1 \mu \mathrm{M} \mathrm{ZnSO}$. Western blotting was performed to monitor purification steps using a commercial antiHIS antibody (GE). Furthermore, the identity of the eluted protein was assigned by automated EDMAN degradation.

\section{4. $\mathrm{H}^{14} \mathrm{CO}_{3}^{-}$binding assays}

Soluble protein extract containing $\mathrm{His}_{6}$-tagged $\gamma \mathrm{CA} 2$ (21 kDa) was incubated at $4{ }^{\circ} \mathrm{C}$ with a Ni affinity resin (GE Healthcare) for $1 \mathrm{~h}$. Resin-Bound $\gamma \mathrm{CA} 2$ was incubated with $\mathrm{NaH}^{14} \mathrm{CO}_{3}$ as previously described [13]. The radioactivity of ${ }^{14} \mathrm{C}$ was measured with a scintillation counter Beckman LS 7000.

\subsection{Fluorometric CA activity assays}

The dehydration of bicarbonate reaction was followed by measuring the $\mathrm{pH}$ change using a fluorescent $\mathrm{pH}$-indicator, 8-hydroxypyrene-1,3,6-trisulfonate (pyranine) [18]. Fluorescence measurements were collected with an AMINCO-Bowman Series 2 Luminescence Spectrofluorometer equipped with a Bio SX-18 MV stopped flow (Applied photophysics). The reaction was started by mixing a solution containing $\mathrm{KHCO}_{3}$ in $0.5 \mathrm{mM}$ bicine- $\mathrm{KOH}$ at $\mathrm{pH} 8$ with an equal volume of $100 \mathrm{nM}$ pyranine with or without enzyme in $0.5 \mathrm{mM}$ HEPES-KOH at $\mathrm{pH}$ 6.0. The fluorescence intensity change was followed by measuring fluorescent emission at $512 \mathrm{~nm}$ after excitation at $466 \mathrm{~nm}$.

\subsection{Esterase activity}

Activity for p-nitrophenylacetate hydrolysis was determined at $25{ }^{\circ} \mathrm{C}$ in a reaction mixture $(1.35 \mathrm{ml})$ containing $0.5 \mathrm{ml}$ of freshly prepared $3 \mathrm{mM}$ p-nitrophenylacetate in aqueous 3\% (vol/vol) acetone and $0.85 \mathrm{ml}$ of water. The uncatalyzed rate of the reaction was determined by adding $0.15 \mathrm{ml}$ of $100 \mathrm{mM}$ potassium phosphate $(\mathrm{pH} 7.0)$ containing $1 \mathrm{mM}$ zinc sulfate and recording the 
change in $\mathrm{A}_{348}$ per $\min \left(\Delta \varepsilon 5000 \mathrm{M}^{-1} \mathrm{~cm}^{-1}\right)$. After $2 \mathrm{~min}, 15 \mu \mathrm{l}$ of enzyme solution was added, and the catalyzed reaction was monitored for additional $3 \mathrm{~min}$ [19].

\section{Results}

To provide insight into the function of $\gamma$ CAs in plants, the cDNA encoding one complex I subunit, $\gamma \mathrm{CA} 2$, was cloned in an expression vector containing a removable $6 \mathrm{XHis}$ tag at the N-terminus. Mitochondrial signal peptide predictions and alignments with crystallized protein homologues [2EG0, 1V3W, 1XHD and 1QRL (CAM)] were used with in order to find structural restriction to perform $\gamma$ CA2 deletions (Fig. 1 ).

Since the full-length cDNA produced a $30 \mathrm{kDa}$ recombinant protein in inclusion bodies, several deletions were assayed to obtain soluble proteins. According to the alignment analysis, a series of three constructs were performed: (2-218, 18-218 and 50-218) which were termed according to the first and last amino acid positions. Only the construct 50-218 (coding for a $21 \mathrm{kDa}$ protein) was expressed as a soluble protein (Fig. 2A and B). This recombinant protein contains all the predicted amino acids important for catalysis and $\mathrm{Ci}$ binding (Fig 1). However, it does lack the predicted signal peptide and the non-conserved C-terminus. Accordingly, it was chosen for further analyses.

\subsection{Purification of soluble $\gamma C A 2$}

The E. coli strain containing the 50-218 construct induced with IPTG as indicated in Section 2 as grown ON at $20^{\circ} \mathrm{C}$ and subjected to lysis. Soluble proteins were applied to a Ni-column in order to retain the recombinant His-tagged protein. A great proportion ( $\sim 98 \%)$ was eluted with Imidazole. A $21 \mathrm{kDa}$ protein is recognized in a Western blot using the commercial anti-His-tag antibody (Fig. 2C). The protein was stable at $4{ }^{\circ} \mathrm{C}$ for more than 10 days without any sign of proteolysis or precipitation. A relatively low yield of about $1 \mathrm{mg} / 4 \mathrm{l}$ of culture was routinely obtained.

\subsection{Recombinant plant $\gamma C A 2$ forms stable homotrimers}

The best biochemical and structurally characterized $\gamma$ CA is CAM from the methanogenic archeon $M$. thermophila (for a review see [4]). This protein was crystallized and shown to form homotrimers
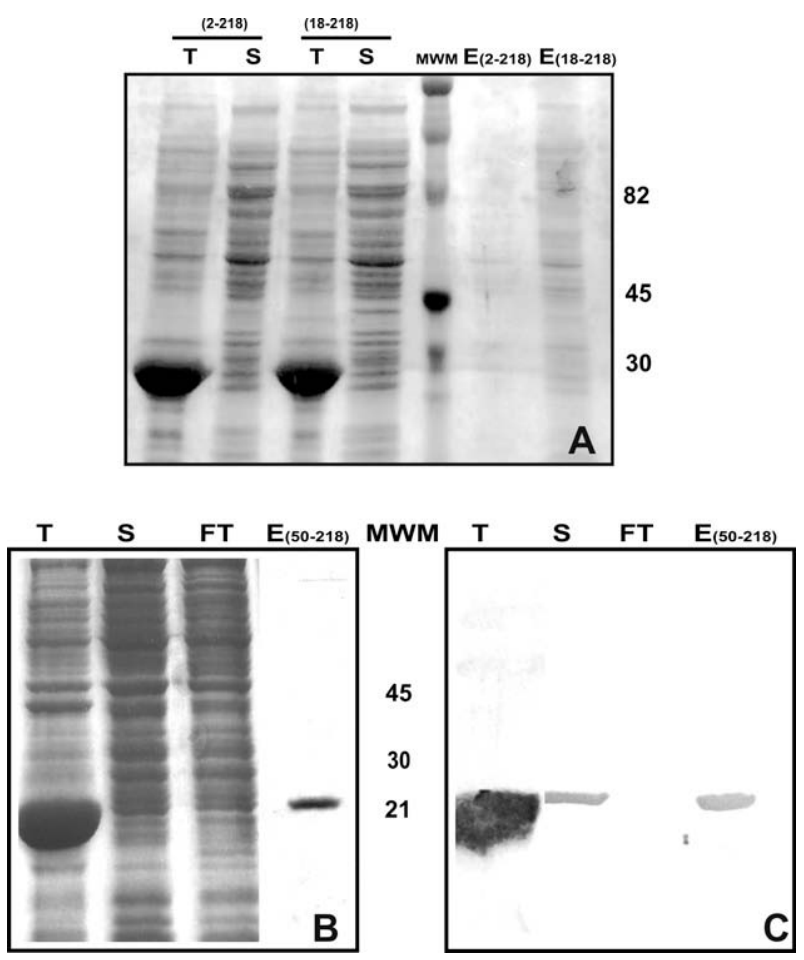

Fig. 2. Expression and purification of $\gamma \mathrm{CA} 2$. (A) Coomasie blue stain of insoluble recombinantly expressed $\gamma$ CA2 (2-218 and 18-218). T: whole bacterial cell lysate. $\mathrm{S}$ : whole bacterial soluble cell lysate. E: Eluted fraction. (B and C) Coomasie stain of soluble recombinantly expressed $\gamma \mathrm{CA} 2(50-218)$ and Western blot revealed with Anti -His Antibody. T: whole bacterial cell lysate. S: whole bacterial soluble cell lysate. FT: Flow through of Ni-column. E: Eluted fraction. MWM: Molecular weight marker. In all case the SDS-PAGE was performed at $10 \%$.

that are essential for activity. In order to know the oligomerization state of recombinant $\gamma$ CA2, Dynamic light scattering was used. A spherical particle of $3.4 \mathrm{~nm}$ corresponding to $\sim 58 \mathrm{kDa}$ was mainly seen (96.3\% in mass) (Fig. 3A). Furthermore, purified recombinant $\gamma$ CA2 was applied to a Superose 12 column. A specie of $\sim 57 \mathrm{kDa}$ was clearly detected (Fig. 3B). Accordingly, it was concluded that recombinant $\gamma$ CA2 folded in the form of homotrimers as previously predicted [6].

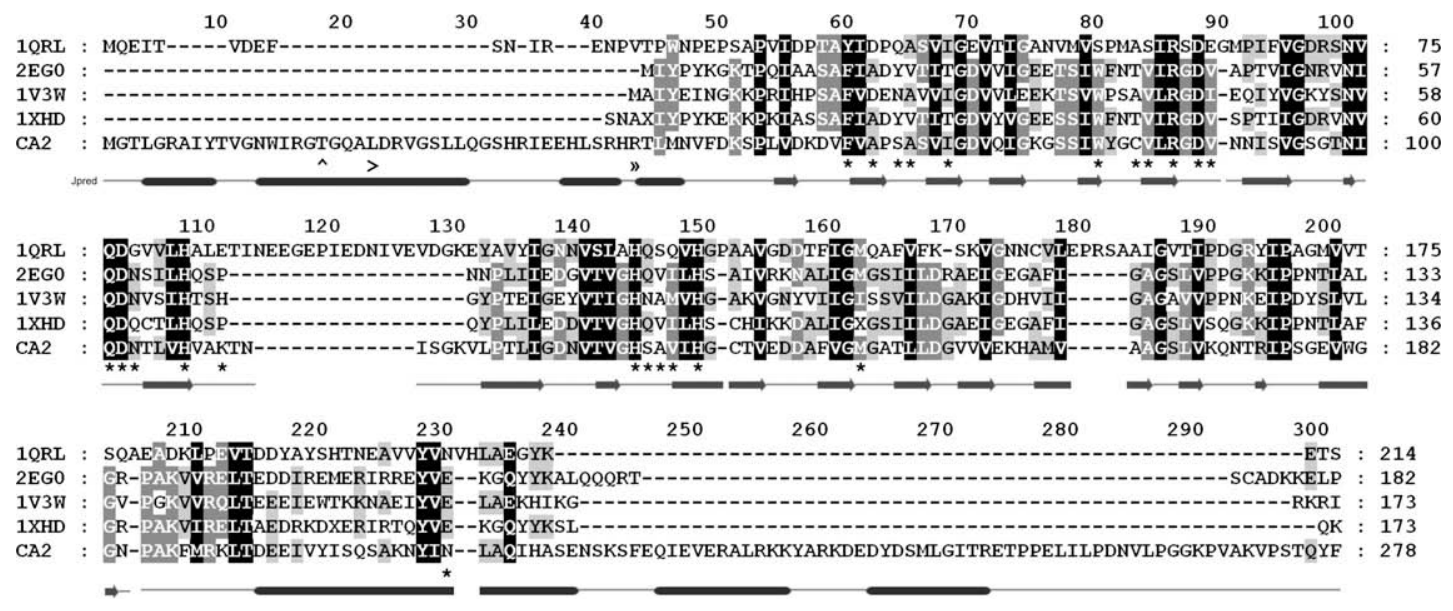

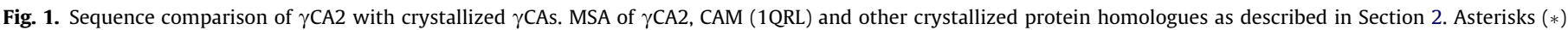

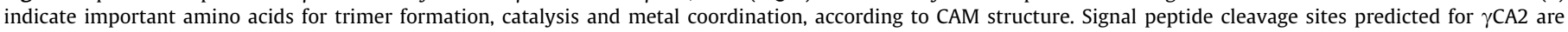
marked: MitoProt, ^; SignalP, >; TargetP, ». Secondary structure predicted for $\gamma$ CA2 by Jpred: cylinders, $\alpha$-helix; arrows, $\beta$-sheet. 

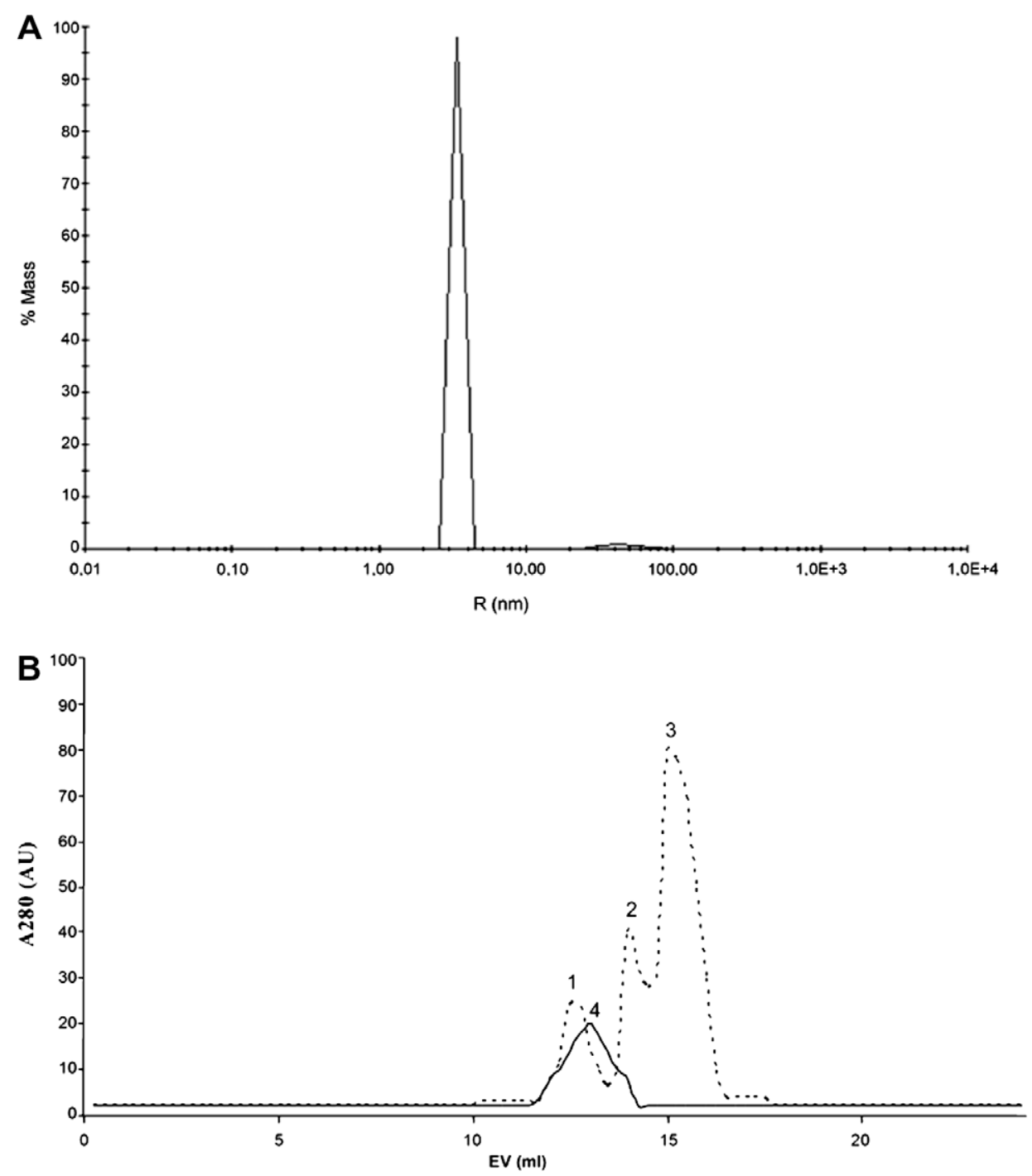

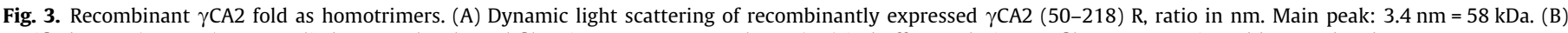

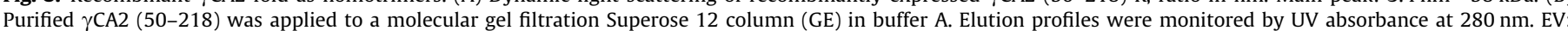

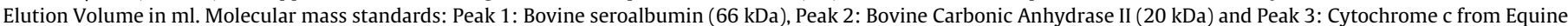
heart (12 kDa).

\section{3. $\gamma C A 2$ homotrimers do not exhibit detectable bicarbonate dehydration}

The dehydration reaction of bicarbonate was assayed in the absence of enzyme (spontaneous reaction, SR), and in the presence of either $\gamma$ CA2 or Bovine Carbonic Anhydrase (BCAII). As shown in Fig. 4, the presence of $\gamma C A 2$ in the reaction mixture does not produce a significant change in the initial velocity of dehydration reaction of bicarbonate respect to the spontaneous reaction $(0.0682$ S.D. $0.0005 \mathrm{au} \mathrm{s}^{-1}$ and 0.0581 S.D. $0.0003 \mathrm{au} \mathrm{s}^{-1}$, respectively, $n=3)$. The same observations were achieved at several concentrations of $\gamma \mathrm{CA} 2(1-10 \mu \mathrm{M})$ and $\mathrm{NaHCO}_{3}(5$ and $10 \mathrm{mM}$ ) (data not shown). Notice that sevenfold less of BCA in the reaction mixture produces a noticeable increase of the initial velocity (0.319 S.D. $0.005 \mathrm{au} \mathrm{s}^{-1}$ ). It was thus concluded that recombinant plant $\gamma \mathrm{CA} 2$ homotrimers do not exhibit carbonic anhydrase activity, at least, in the conditions tested.

Some carbonic anhydrases from mammalian sources catalyse the reversible hydrolysis of esters [20]. With p-nitrophenylacetate as a substrate, commercially available Bovine Carbonic Anhydrase showed an esterase activity of $34.7 \mathrm{~mol}$ of p-nitrophenylacetate per min per mol of enzyme, in contrast no activity was detected for the plant enzyme $(0.02 \mathrm{~mol}$ of p-nitrophenylacetate per min per mol). Thus, $\gamma$ CA2 is one of several carbonic anhydrases [14] for which esterase activity appears to be absent.

\section{4. $\gamma C A 2$ is able to bind inorganic carbon}

Structural and amino acid sequence comparisons indicated that all of the CAM residues involved in $\mathrm{Zn}$ coordination, binding of $\mathrm{HCO}_{3}^{-}$and the formation homotrimer are spatially conserved in $\gamma C A 2$ [6]. Thus, bio-informatic analyses support the view that $\gamma \mathrm{CA} 2$ homotrimers may retain $\mathrm{HCO}_{3}^{-} / \mathrm{CO}_{2}$ binding capability, although the experimental evidence indicates that recombinant $\gamma$ CA2 (50-218) is apparently unable to catalyse the reversible $\mathrm{CO}_{2}$ hydration (Fig. 4). When incubated with $\mathrm{H}^{14} \mathrm{CO}_{3}^{-}$, resinretained, recombinant $\gamma \mathrm{CA} 2$ binds $2.4 \times 10^{-5}$ nanomol of $\mathrm{Ci}$ per ng of $\gamma$ CA2 protein (S.D. $1.71 \times 10^{-6}, n=5$ ), corresponding to $17.95 \pm 2.74$ picomol in total. This level of binding was threefold greater than that observed for the resin alone or resin-retained $E$. coli background proteins, on an equal volume basis (Fig 5). Due to the spontaneous $\mathrm{HCO}_{3}^{-}$dehydration to form $\mathrm{CO}_{2}$, the exact nature of the bonded molecule to $\gamma \mathrm{CA} 2$ remains elusive. 


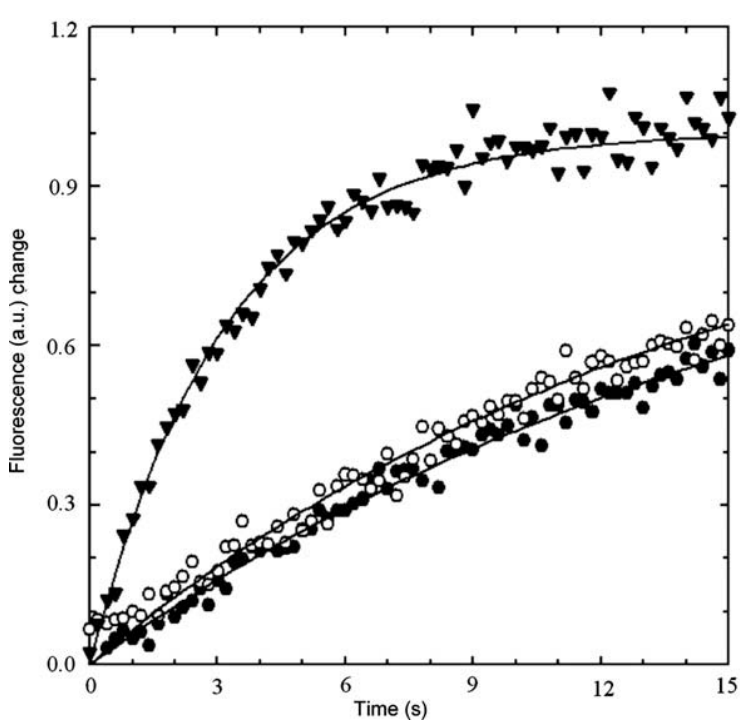

Fig. 4. Fluorometric carbonic anhydrase activity assay. Changes in pyranine fluorescence intensity as a function of time were obtained in media containing $20 \mathrm{mM} \mathrm{KHCO}{ }_{3}$ and either ( $) 3 \mu \mathrm{g} / \mathrm{ml}$ of Bovine Carbonic Anhydrase II BCA II, (O) $20 \mu \mathrm{g} / \mathrm{ml}$ of $\gamma \mathrm{CA} 2$ or $(\bullet)$ without protein (SR). The continuous lines are plots of equation, signal $=A\left(1-e^{-k \text { time }}\right)+C$ for the best fitting values of the parameters $A$ and $k$. Each fluorescence trace was normalized to the maximum increase in fluorescence $(A)$.Values of initial velocity ( $v i)$ were calculated as: $v i=A \times k$.

A

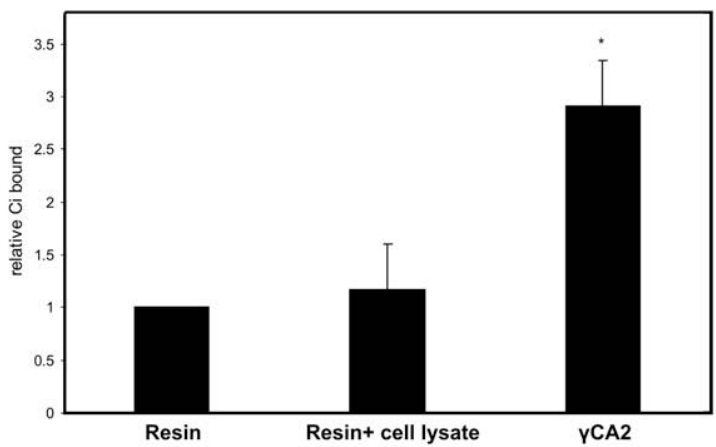

B

\begin{tabular}{|c|c|c|c|}
\hline Treatment & Resin & Resin + cell lysate & YCA2 \\
\hline pmol Ci $\pm S D$ & $6.182 \pm 2.99$ & $7.226 \pm 2.69$ & $17.95 \pm 2.74$ \\
\hline
\end{tabular}

C

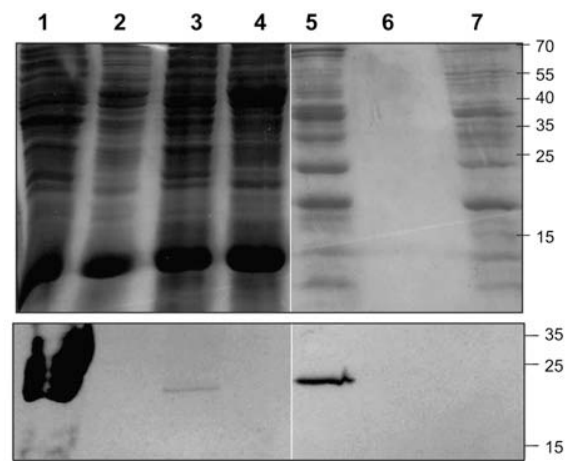

Fig. 5. ${ }^{14} \mathrm{C}$ carbonate binding assay. (A) Relative $\left({ }^{14} \mathrm{C}\right)$ carbon inorganic (Ci) bound respect to the control. (B) Quantitative amount of $\mathrm{Ci}$ expressed in picomol. (C) Coomasie stain (top) and Western blot analysis with Anti-His (bottom). 1: overexpressed $\gamma$ CA2 bacterial cell lysate, 2: bacterial cell lysate, 3: overexpressed $\gamma$ CA2 bacterial cell lysate after incubation with $\mathrm{Ni}$-resin, 4: bacterial cell lysate after incubation with Ni-resin, 5: $\gamma$ CA2 bound to the resin, 6: Resin alone, 7: resin + bacterial cell lysate.

\section{Discussion}

In this work, a functional characterization of gamma carbonic anhydrase subunit of plant mitochondrial complex I, $\gamma$ CA2 was performed. Recombinant homotrimers of $\gamma \mathrm{CA} 2$ are able to bind carbon dioxide/bicarbonate, however, they appear to be unable to catalyse the reversible bicarbonate dehydration in the conditions tested. These results could suggest that the so-called eukaryotic $\gamma$ CAs, in plants, do not function as bona fide carbonic anhydrases, however, with a related activity.

In Chlamydomonas as well as in Arabidopsis $\beta C A$ and $\gamma C A$ families were described [6,7,21-23]. In Chlamydomonas there are two mitochondrial $\beta C A s$ encoded by nuclear genes which are expressed in the light at low external $\mathrm{CO}_{2}$ concentrations [24,25]. In Arabidopsis only one of six active genes, At $\beta C A 6$, encode a product which is imported into mitochondria [23]. Different hypothesis were suggested concerning the function of mitochondrial $\beta C A s$ : (i) buffering matrix $\mathrm{H}^{+}$concentration upon initiation of photorespiration [21] or depending on $\mathrm{NH}_{4}{ }^{+}$concentration [26]; (ii) $\mathrm{HCO}_{3}^{-}$formation for anaplerotic reactions [26]; (iii) limiting loss of $\mathrm{CO}_{2}$ produced by photorespiration [27]. The latter hypotheses require the presence of a bicarbonate transporter within the mitochondrial membranes, which so far has not been described. Bicarbonate could thus be transported actively from mitochondria to the cytoplasm and afterwards into plastids, allowing recycling of excess of mitochondrial $\mathrm{CO}_{2}$ for carbon-fixation by RubisCO.

\subsection{Possible function of $\gamma C A$ proteins}

Phylogenetic studies revealed the conservation of relevant active site residues of the large family of $\gamma$ CAs [6,8]. All members contain the three His residues (or conservative replacements) important to bind a metal ion. Cyanobacterial CcmM shows a C-terminal region which may serve to interact with RubisCO and an $\mathrm{N}-$ terminal region similar to $\gamma$ CAs $[28,29]$. It does contain all the catalytically important residues described previously, except those involved in proton transfer [30-32]. Conversely, mitochondrial $\gamma$ CAs are integral proteins of complex I. All five $\gamma \mathrm{CA} / \gamma \mathrm{CALs}$ contain an $\mathrm{N}-$ terminal extension which may function as mitochondrial signal peptide $[6,10]$ and a C-terminal extension which is most likely required to anchor the proteins to the membrane arm of complex I [7]. In addition, putative $\gamma$ CAs from $\alpha$ and $\gamma$ proteobacteria (considered as mitochondrial ancestors) and from plant and green algae mitochondria lack the Glu residues essential for proton transfer. However, the Tyr 159 of $\gamma C A 2$, postulated as proton transfer residue [6] is conserved in all $\gamma$ CA homologues with the intriguing exception of CAM, which is the only example showing CA activity.

Could these modifications in proton shuttle residues mean that all other homologous sequences encode for proteins with another but related activity? Experimental evidences from both, cyanobacteria [13] and plants (this work) suggest that this could be the case. Neither the CcmM protein nor $\gamma \mathrm{CA} 2$ seem to exhibit reversible carbon dioxide hydration but both of them are able to bind carbonate and/or carbon dioxide at similar levels suggesting a related activity. Furthermore, their transcription was shown to be dependent on $\mathrm{CO}_{2}$ concentration $[11,29,33]$. The $\mathrm{CcmM}$ protein is proposed to transport bicarbonate from the cytoplasm to the centre of the carboxysome where a conserved $\beta C A$, the CcaA protein, efficiently converts bicarbonate into carbon dioxide and thus, RubisCO could fixate through the Calvin Cycle [13].

In eukaryotes, RubisCO, especially at low $\mathrm{CO}_{2}$, is able to use molecular $\mathrm{O}_{2}$ and initiates a glycolate cycle or photorespiration which involves the glyoxysome and finishes in the mitochondria. Within this organelle, decarboxylation of two molecules of glycine occurs to give serine, ammonium and carbon dioxide which is most 
likely rapidly converted in bicarbonate by a mitochondrial $\beta C A$ which has been suggested to be At $\beta C A 6$ [23]. The $\mathrm{CO}_{2}$ could be recycled to increase the efficiency of photosynthetic carbon-fixation. However, this hypothesis requires the presence of a bicarbonate transporter across the inner mitochondrial membrane which, as $\mathrm{CcmM}$, transports the bicarbonate from one side to another. Mitochondria represent an important source of $\mathrm{CO}_{2}$ for photosynthesis [34]. Accordingly, it is proposed that plant complex I integrated $\gamma \mathrm{CAs}$ may function together with mitochondrial $\beta C A s$ in $\mathrm{CO}_{2}$ recycling.

The CA domain seems to be a general feature of plant complex I, since it now was described for the $C_{3}$ plant Arabidopsis, the $C_{4}$ plant maize and the green alga Polytomella $[1,7,35]$. If the CA domain is important in photorespiration, a difference should be observed between mitochondrial complex I from $C_{3}$ and $C_{4}$ plants. The latter show anatomical and biochemical specializations to avoid photorespiration, pre-fixation in four carbon compounds in mesophyll cells and $\mathrm{CO}_{2}$ fixation by RubisCO in bundle sheath cells. However, Peters et al. [35] suggest that $\gamma$ CA function in these two kinds of plants might be different, in $\mathrm{C}_{3}$ plants in the context of photorespiration and in $\mathrm{C}_{4}$ plants in the $\mathrm{CO}_{2}$ liberation step in the bundle sheath cells [36]. Furthermore, it would be interesting to know the tissue specific expression pattern of maize $\gamma$ CAs which may differ between bundle sheath and mesophyll cells.

Thus, it is proposed that complex I integrated $\gamma$ CAs could eventually represent this elusive bicarbonate transporter with the following characteristics: (1) attached to the membrane and/or complex I membrane arm by a C-terminal extension only present in plant $\gamma$ CAs [7], (2) binding of bicarbonate at comparable level to CcmM and (3) do not show bicarbonate dehydration activity being thus most likely able to transport this molecule without further changes.

\section{Acknowledgements}

We would like to thank Verónica Augusto for critical reading of the manuscript. This work was supported by Grants from the National Agency for Science and Technology (ANPCyT, PICT 31669 and 00673), the Ministry of Science and Technology, ArgentineECOS Sud France (MinCyT-ECOS A06B03) and the University of Mar del Plata, Argentine (OCS 341/08). V.M. and F.V. are doctoral fellows, S.K., R.G.L. and E.Z. are members of CONICET.

\section{References}

[1] Dudkina, N., Eubel, H., Keegstra, W., Boekema, E.J. and Braun, H.P. (2005) Structure of a mitochondrial supercomplex formed by respiratory-chain complexes I and III. Proc. Natl. Acad. Sci. USA 102, 3225-3229.

[2] So, A.K., Espie, G.S., Williams, E.B., Shively, J.M., Heinhorst, S. and Cannon, G.C (2004) A novel evolutionary lineage of carbonic anhydrase (epsilon class) is a component of the carboxysome shell. J. Bacteriol. 186, 623-630.

[3] Sawaya, M.R., Cannon, G.C., Heinhorst, S., Tanaka, S., Williams, E.B., Yeates, T.O. and Kerfeld, C.A. (2006) The structure of beta carbonic anhydrase from the carboxysomal shell reveals a distinct subclass with one active site for the price of two. J. Biol. Chem. 281, 7546-7555.

[4] Zimmerman, S.A. and Ferry, J.G. (2008) The beta and gamma classes of carbonic anhydrase. Curr. Pharm. Des. 14, 716-721.

[5] Elleuche, S. and Pöggeler, S. (2009) Evolution of carbonic anhydrases in fungi. Curr. Genet. 55, 211-222.

[6] Parisi, G., Perales, M., Fornasari, M.S., Colaneri, A., González-Schain, N., GómezCasati, D., Zimmermann, S., Brennicke, A., Araya, A., Ferry, J.G., Echave, J. and nad Zabaleta, E. (2004) Gamma carbonic anhydrases in plant mitochondria. Plant Mol. Biol. 55, 193-207.

[7] Sunderhaus, S., Dudkina, N.V., Jänsch, L., Klodmann, J., Heinemeyer, J., Perales, M., Zabaleta, E., Boekema, E.J. and Braun, H.P. (2006) Carbonic anhydrase subunits form a matrix-exposed domain attached to the membrane arm of mitochondrial complex I in plants. J. Biol. Chem. 281, 6482-6488.

[8] Heazlewood, J.L., Howell, K.A. and Millar, A.H. (2003) Mitochondrial complex I from Arabidopsis and rice. orthologs of mammalian and fungal components coupled with plant-specific subunits. Biochim. Biophys. Acta 1604, 159-169.

[9] Perales, M., Parisi, G., Fornasari, M.S., Colaneri, A., Villarreal, F., GonzálezSchain, N., Echave, J., Gómez-Casati, D., Braun, H.P., Araya, A. and Zabaleta, E. (2004) Gamma carbonic anhydrase like complex interact with plant mitochondrial complex I. Plant Mol. Biol. 56, 947-957.
[10] Braun, H.P. and Zabaleta, E. (2007) Carbonic anhydrase subunits of the mitochondrial NADH dehydrogenase complex (complex I) in plants. Physiol. Plant 129, 114-122.

[11] Perales, M., Eubel, H., Heinemeyer, J., Colaneri, A., Zabaleta, E. and Braun, H.P. (2005) Disruption of a nuclear gene encoding a mitochondrial gamma carbonic anhydrase reduces complex I and supercomplex $\mathrm{I}-\mathrm{III}_{2}$ levels and alters mitochondrial physiology in Arabidopsis. J. Mol. Biol. 350, 263-277.

[12] Villarreal, F., Martin, V., Perales, M., Colaneri, A., González-Schain, N., Martin M., Bartoli, C., Braun, H.P. and Zabaleta, E. (2009) Ectopic expression of $\gamma$ CA2 causes male sterility by anther indehiscence. Plant Mol. Biol. 70, 471-485.

[13] Cot, S.S., So, A.K. and Espie, G.S. (2008) A multiprotein bicarbonate dehydration complex essential to carboxysome function in cyanobacteria. J Bacteriol. 190, 936-945.

[14] Tripp, B., Smith, K. and Ferry, J.G. (2001) Carbonic anhydrase: new insights for an ancient enzyme. J. Biol. Chem. 276, 48615-48618.

[15] Laemmli, U.K. (1970) Cleavage of structural proteins during the assembly of the head of bacteriophage T4. Nature 227, 680-685.

[16] Notredame, C., Higgins, D.G. and Heringa, J. (2000) T-coffee: a novel method for fast and accurate multiple sequence alignment. J. Mol. Biol. 302, 205-217.

[17] Cole, C., Barber, J.D. and Barton, G.J. (2008) The Jpred 3 secondary structure prediction server. Nucleic Acids Res. doi:10.1093/nar/gkn238.

[18] Shingles, R. and Moroney, J.V. (1997) Measurement of carbonic anhydrase activity using a sensitive fluorometric assay. Anal. Biochem. 252, 190-197.

[19] Armstrong, J.M., Myers, D.V., Verpoorte, J.A. and Edsall, J.T. (1966) Purification and properties of human erythrocyte carbonic anhydrases. J. Biol. Chem. 241 5137-5149.

[20] Pocker, Y. and Sarkanen, S. (1978) Carbonic anhydrase: structure, catalytic versatility, and inhibition. Adv. Enzymol. 47, 149-274.

[21] Eriksson, M., Karlsson, J., Ramazanov, Z., Gardestrom, P. and Samuelsson, G. (1996) Discovery of an algal mitochondrial carbonic anhydrase: molecular cloning and characterization of a low- $\mathrm{CO}_{2}$-induced polypeptide in Chlamydomonas reinhardtii. Proc. Natl. Acad. Sci. USA 93, 12031-12034.

[22] Cardol, P., Vanrobaeys, F., Devreese, B., Van Beeumen, J., Matagne, R.F. and Remacle, C. (2004) Higher plant-like subunit composition of mitochondrial complex I from Chlamydomonas reinhardtii: 31 conserved components among eukaryotes. Biochim. Biophys. Acta 1658, 212-224.

[23] Fabre, N., Reiter, I., Becuwe-Linka, N., Genty, B. and Rumeau (2007) Characterization and expression analysis of genes encoding $\alpha$ and $\beta$ carbonic anhydrases in Arabidopsis D. Plant Cell Environ. 30, 617-629.

[24] Villand, P., Eriksson, M. and Samuelsson, G. (1997) Carbon dioxide and light regulation of promoters controlling the expression of mitochondrial carbonic anhydrase in Chlamydomonas reinhardtii. Biochem. J. 327, 51-57.

[25] Eriksson, M., Villand, P., Gardestrom, P. and Samuelsson, G. (1998) Induction and regulation of expression of a low- $\mathrm{CO}_{2}$-induced mitochondrial carbonic anhydrase in Chlamydomonas reinhardtii. Plant Physiol. 116, 637-641.

[26] Giordano, M., Norici, A., Forssen, M., Eriksson, M. and Raven, J.A. (2003) An anaplerotic role for mitochondrial carbonic anhydrase in Chlamydomonas reinhardtii. Plant Physiol. 132, 2126-2134.

[27] Raven, J.A. (2001) A role for mitochondrial carbonic anhydrase in limiting $\mathrm{CO}_{2}$ leakage from low $\mathrm{CO}_{2}$-grown cells of Chlamydomonas reinhardtii. Plant Cell Environ. 24, 261-265.

[28] Ludwig, M., Sültemeyer, D. and Price, G.D. (2000) Isolation of ccmKLMN genes from the marine cyanobacterium Synechococcus sp. PCC7002 (Cyanophyceae) and evidence that CcmM is essential for carboxysome assembly. J. Phycol. 36, 1109-1118.

[29] Price, G.D., Badger, M.R., Woodger, F.J. and Long, B.M. (2008) Advances in understanding the cyanobacterial $\mathrm{CO}_{2}$-concentrating-mechanism (CCM): functional components, $\mathrm{Ci}$ transporters, diversity, genetic regulation and prospects for engineering into plants. J. Exp. Bot. 59, 1441-1461.

[30] Iverson, T.M., Alber, B.E., Kisker, C., Ferry, J.G. and Rees, D.C. (2000) A closer look at the active site of gamma-class carbonic anhydrases: high-resolution crystallographic studies of the carbonic anhydrase from Methanosarcina thermophila. Biochemistry 39, 9222-9231.

31] Tripp, B.C. and Ferry, J.G. (2000) A structure-function study of a proton transport pathway in the $\gamma$-class carbonic anhydrase from Methanosarcina thermophila. Biochemistry 39, 9232-9240.

[32] Tu, C., Rowlett, R.S., Tripp, B.C. and Ferry, J.G. (2002) Chemical rescue of proton transfer in catalysis by carbonic anhydrases in the beta- and gamma-class. Biochemistry 41, 15429-15436.

[33] Woodger, F.J., Badger, M.R. and Price, G.D. (2003) Inorganic carbon limitation induces transcripts encoding components of the $\mathrm{CO}_{2}$-concentrating mechanism in Synechococcus sp. PCC7942 through a redox independent pathway. Plant Physiol. 133, 2069-2080.

[34] Riazunnisa, K., Padmavathi, L., Bauwe, H. and Raghavendra, A.S. (2006) Markedly low requirement of added $\mathrm{CO}_{2}$ for photosynthesis by mesophyl protoplasts of pea (Pisum sativum): possible roles of photorespiratory $\mathrm{CO}_{2}$ and carbonic anhydrase. Phys. Plant 128, 763-772.

[35] Peters, K., Dudkina, N.V., Jänsch, L., Braun, H.P. and Boekema, E.J. (2008) A structural investigation of complex I and I? III2 supercomplex from Zea mays at 11-13 $\AA$ resolution: assignment of the carbonic anhydrase domain and evidence for structural heterogeneity within complex I. Biochim. Biophys. Acta 1777, 84-93.

[36] Edwards, G.E., Furbank, R.T., Hatch, M.D. and Osmond, C.B. (2001) What does it take to be $\mathrm{C}_{4}$ ? Lessons from the evolution of $\mathrm{C}_{4}$ photosynthesis. Plant Physiol. $125,46-49$ 